\title{
Cover system performance - using numerical modelling to optimise monitoring systems
}

\author{
P Garneau O'Kane Consultants, Australia \\ K Albano O'Kane Consultants, Australia \\ WT Moore Newmont Asia Pacific, Australia
}

\begin{abstract}
Lysimeters are widely used in the mining and waste industries to directly measure the performance of cover systems installed for rehabilitation of containment facilities (the facility) to restrict net percolation (deep infiltration) and oxygen flux. As lysimeters are conceptually simple, stakeholders place significant emphasis on performance measured by these systems, which adds to the importance of obtaining representative net percolation values. However, the design of lysimeters for cover system monitoring programs in the mining industry often does not consider fundamental aspects of lysimeter design, leading to inaccurate measurement of percolation. Lysimeters also require complementary soil monitoring equipment in order to measure multiple parameters of a cover system's water balance, and thus its overall performance.

Newmont Boddington Gold Mine, located in Western Australia, implemented rehabilitation field trials for assessing the performance of an updated closure strategy for its Waste Rock Dumps (WRD). The extensive monitoring required for assessment of the cover system performance included the design and installation of a lysimeter to measure percolation. Sizing, that is the depth and area dimensions of the lysimeter, was completed through numerical modelling. Numerical modelling is used to ensure that the lysimeter performs to expectations under a wide range of conditions encountered during the life of the facility.

O'Kane Consultants completed an integrated numerical assessment to develop the monitoring system design for performance monitoring of the WRD cover system. Completion of a performance analysis was required for selection of the optimal lysimeter design whilst considering installation and cost. Numerical modelling was undertaken to simulate and compare the relative performance of various lysimeter configurations. Geostudio's VADOSE/W and SEEP/W, two commercially available software packages, were coupled to simulate long-term percolation through the cover system and seepage rates through the lysimeter's base. This paper presents the methodology utilised, results of numerical simulations of lysimeter designs and final design of the performance monitoring system.
\end{abstract}

\section{Introduction}

Mine closure planning has become an important management tool for modern mine development to achieve successful closure. The early identification of risks associated with mine closure is essential to allowing early planning for progressive rehabilitation and risk mitigation. Uncertainties associated with projecting the effectiveness of mitigation measures can be assessed using actual measurements from pilot scale field trials, providing increasingly more accurate mine closure costs (the costs).

The construction of mine waste cover systems are often an integral component of the design criteria required to meet mine closure objectives. In general, cover systems are constructed in such circumstances to minimise the influx of meteoric water to the underlying waste as percolation. This is achieved by reducing net percolation of meteoric water to attenuate the peak concentrations for contaminants of concern in natural receptors to levels that can be assimilated without adverse impact to the receiving environment ( $O^{\prime}$ Kane \& Ayres 2012). As part of mine closure planning, all relevant stakeholders should have their interests considered to ensure successful long-term management of the mine closure plan. 
There are two main challenges to cover systems for mine wastes: cost and the uncertainty with respect to long-term performance. Building a cover system typically represents a substantial component of the costs. However, the costs associated with the potential environmental liability from a cover system not meeting its performance criteria can be much more significant from a mine-life cycle perspective. Therefore, cover systems should be designed on the basis of the best available site-specific information for material properties, climate and pilot scale field trials. Models and pilot-scale field trials are often used to guide design due to their low cost and shorter construction timelines compared to building a cover system over the entire containment facility. However, use of pilot-scale field trial results to predict full-scale (e.g. watershed) cover performance can be problematic due to an inherent disconnect in measurement scales. Knowledge and confidence with respect to long-term performance of cover systems is often limited due to a lack of appropriate performance monitoring over an extended time frame spanning years and climactic extremes. In order to increase knowledge and confidence in the cover system performance for a given site, installation of a lysimeter as part of the performance monitoring system is often specified by stakeholders. Their operating principles are relatively well understood as measurements are a direct reflection of the cover system performance.

A lysimeter is a physical container that is installed at depth within a cover profile and is designed to collect water that has percolated vertically through the soil. At regular intervals, the water that has entered the lysimeter is measured, and the amount of water collected over a given time frame is interpreted to be equal to the percolation rate that has occurred through the surrounding cover profile. The measured infiltration rate can then be used to evaluate situations such as the effectiveness of an engineered soil cover system or to predict the movement of contaminants with time. Because a lysimeter is buried at depth, it is not possible to visually evaluate and witness its performance. Interpretation of performance depends entirely on having an understanding of the processes involved and the properties controlling percolation. In the past, questions were raised about the effectiveness and reliability of lysimeters as appropriate monitoring devices. The use of a finite element model such as VADOSE/W and SEEP/W (Geo-Slope International Ltd 2014a, 2014b), is instrumental in learning more about how a lysimeter is performing, in helping understand the dominant processes involved and for ensuring that a given lysimeter design is appropriate for its intended purpose.

\section{Review of theory}

\subsection{Cover system water balance}

Direct measurement of cover system field performance is achieved through monitoring multiple components of the water balance (Figure 1) so that key indicators of cover system performance (e.g. percolation) can be understood with a high level of confidence. Cover system performance monitoring should attempt to measure multiple parameters in order to increase the confidence in the cover system water balance. Some parameters are more difficult to measure with an acceptable degree of confidence and measuring all parameters of the water balance allows for a cross-check of the data and assists in developing a better understanding of the overall system. 


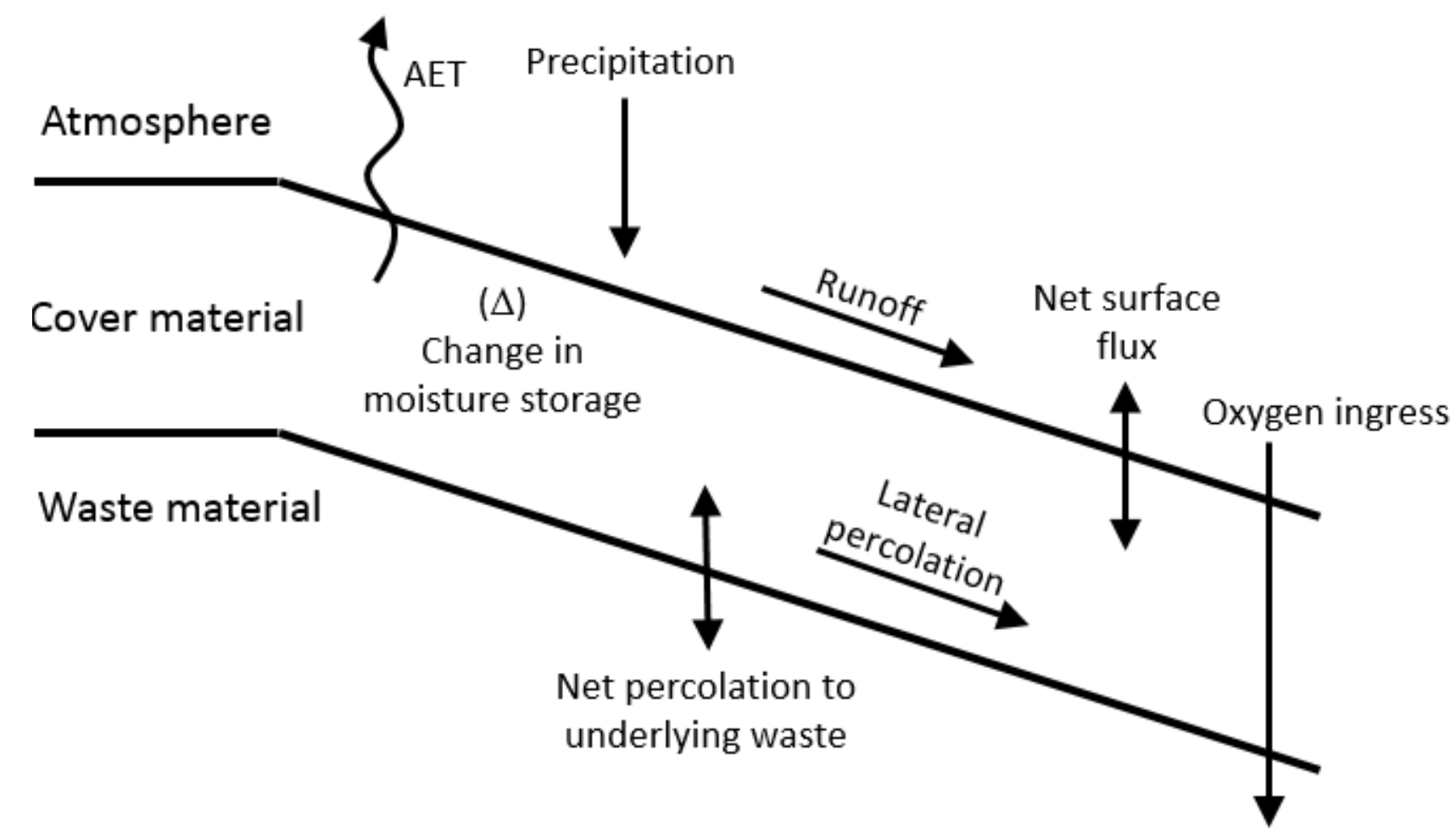

Figure 1 Water balance of a typical cover system

Precipitation is the main input into a cover system water balance. Ideally, rainfall should be measured in multiple locations over the cover system's extent to capture potential spatial differences in rainfall depth and intensity. Rainfall measurement should at least take place in close proximity to the main performance monitoring system in order to develop a specific water balance for the system.

Runoff within a cover system monitoring area is determined by measuring stream flow from the outlet of the small artificial watershed formed by the monitoring area. Flow rate measurement structures are the most common method used for measuring flow rates in small, ephemeral streams and are therefore the most practical method for measuring runoff from small, well defined and isolated watersheds.

The topography and drainage pattern of a cover system would determine the requirement and layout of a monitoring system for lateral percolation (also referred to as interflow). Lateral percolation relates to flow within the cover system that moves parallel to the soil profile layers. Monitoring the lateral percolation rate depends largely on the quantity of lateral percolation and the resolution of measurements required. The lateral percolation is typically measured with a single weeping tile drain aligned parallel to the topographic contour of the area, so that the drain runs perpendicular to the flow of water.

Measurement of soil moisture at different depths in the cover profile, i.e. stored infiltration, is fundamental to the development of a water balance for cover system monitoring. Soil moisture profiles in the waste and cover layers allow one to quantify the volume of water stored within the profile, and can be interpreted to define the rates and direction of water movement in response to plant root uptake, evaporation, percolation, and interflow. Time domain reflectometry sensors are more commonly used for soil moisture measurements in cover performance monitoring for their capacity to be connected to data acquisition systems. Care must be taken to properly calibrate sensor output to field conditions to ensure quantitative measurements are obtained. This is achieved by laboratory testing of field samples following sensor installation. Soil moisture can also be inferred using measurements of in situ matric suction. A matric suction sensor can be thought of as a piezometer of the unsaturated zone in that it measures a stress state variable (i.e. in situ water content is a function of material characteristics and changes in response to suction). 
Net percolation is a critical facet to understanding the water balance of a cover system and is typically a key performance indicator. Net percolation typically refers to water passing through the cover layers of the soil profile and reporting to the waste material. It is often expressed as a percentage of precipitation and is often a metric for stakeholder's understanding of cover system performance; and hence, closure performance.

Evapotranspiration is comprised of two components: evaporation and transpiration. A variety of methods are available for measuring evaporation and evapotranspiration rates from the ground surface. The most commonly utilised methods can be classified as direct measurement methods or micrometeorological methods. Atmometers, evaporation pans, and weighing lysimeters are the most widely used methods for direct measurement of evaporation and evapotranspiration. The most commonly used micrometeorological methods are the Bowen ratio energy balance method, the aerodynamic method, the mass transport method, and the Eddy covariance method (O'Kane 2011).

\subsection{Lysimeter design}

The design and installation of lysimeters to monitor percolation is well understood and implemented in soil science disciplines. The design of a lysimeter for a specific site is not transferable due to potential differences in climatic conditions, hydraulic properties of the cover and waste materials, and the slope of the cover system at the location of the lysimeter. It is the authors' experience that a two-dimensional (2D) saturated/unsaturated seepage/flow model must be used to aid in the design of each lysimeter installed in a cover system (MEND 2004).

\subsubsection{Lysimeter types}

Lysimeters are often used to directly measure net percolation from the base of a cover system into underlying waste material. Lysimeters are a direct measure of cover system performance, and are required to measure representative net percolation rates through the cover systems and low-permeability layers.

Lysimeters come in varying sizes and operating principles. The decision to use a given type will be based on specific site characteristics and requirements; and numerical modelling to determine the best approach. The different types of lysimeters are divided based on their size, construction and installation methods and operating principle.

\subsubsection{Gee lysimeters}

Gee lysimeters use passive capillarity to measure percolation through a layer of soil. They are small in size with a diameter not exceeding $0.20 \mathrm{~m}$ and come as self-contained sensor apparatus. Their relatively low cost of installation makes them an attractive option, but their limited size makes it difficult to capture spatial variability within the soil cover, requiring the installation of multiple sensors. One can argue that installing multiple Gee lysimeters provides understanding on cover system variability, rather than an overall bulk net percolation measurement.

\subsubsection{Tank lysimeters}

As the name suggests, tank lysimeters are typically constructed using heavy duty vertical water storage tanks, generally with a minimum diameter and sidewall height of $2.5 \mathrm{~m}$ and $1.0 \mathrm{~m}$, respectively. A geofabric and drainage sand is placed along the base of the lysimeter to aid drainage by providing a permeable layer that can prevent silting of the drainage system. A drain is placed in the middle of the tank's base and the foundation for the tank is sculpted so that the base is concave, making the central drain the low point of the base. Although they are more likely than Gee lysimeters to capture spatial variability within the soil cover, they typically still require installation of multiple units in order to ensure that potential variability in the cover system is captured. 


\subsubsection{Large scale lysimeters}

Largescale lysimeter are typically in the $100 \mathrm{~m}^{2}$ and over range. They are usually constructed using a frame to form the walls and a synthetic liner of either high-density polyethylene (HDPE) or linear low density polyethylene. The drainage layer at the base of the lysimeter would be constructed with a geofabric placed above and below a sand layer to provide a permeable layer and prevent silting of the drainage layer from fine particle migration. Manufactured drainage nets are also used as an alternative or in addition to a sand layer. A toe drain is used to remove and measure net percolation. The toe drain is a 'concrete boot' with an HDPE top surface for fastening of the geosynthetic collection area. The toe drain reports to a flow measuring device which can be connected to a data acquisition system. The size of a large scale lysimeter makes it more likely to capture spatial variability within the cover system and allows for the use of full-scale earthmoving equipment for construction. Construction of large-scale lysimeters is labour and material intensive as well as time consuming, making them an expensive proposition for performance monitoring in the field. Their installation requires a wide footprint, up to an order of magnitude larger than the footprint of the lysimeter itself.

\subsubsection{Lysimeter collection ratio (LCR)}

The lysimeter collection ratio (LCR) is used as a screening tool to initially evaluate lysimeter designs, and compare anticipated performance of alternative designs. LCR is defined as the ratio of net percolation that would be measured by a lysimeter, as predicted by the model, to the net percolation predicted without the lysimeter present (O'Kane \& Barbour 2003). An LCR of 1.0 would be considered to offer the 'best' performance, as the volume collected by the lysimeter is equal to the flux through the lysimeter boundaries in the model without a lysimeter.

An LCR with values greater than 1.0 and less than 1.0 means that the lysimeter design results in the collection of additional or insufficient water, respectively. While the LCR is a useful indication of lysimeter performance, other aspects of lysimeter design must be considered.

\subsubsection{Modelling design criteria}

There are three criteria used for lysimeter design which compare conditions inside and outside the lysimeter confines. The first criterion is to ensure that the pressure head profiles within and outside the lysimeter are closely matched. This design requirement ensures that bypass flow around the lysimeter resulting from a difference in pressure head profiles is minimised. If the pressure head inside the lysimeter is higher than outside the lysimeter at a given elevation, infiltration will tend to flow around rather than into the lysimeter. Bews et al. (1997) and O'Kane and Barbour (2003) showed that bypass flow around a lysimeter is common if the lysimeter is improperly designed. Bews et al. (1997) used numerical modelling to predict pressure head profiles inside and outside the confines of a lysimeter. The two profiles have to be nearly identical under the range of probable net percolation rates to respect this criterion.

The second criterion is to ensure that the hydraulic gradients inside and outside the lysimeter are closely matched. The gradient within the material below the cover layer should be approximately equal to 1.0 under conditions of steady-state infiltration. When steady-state infiltration occurs within a deep unsaturated profile, the suction eventually becomes constant with elevation. This occurs when the suction developed within the waste is such that the hydraulic conductivity of the waste is equal to the net percolation rate. In this condition, the only gradient required for flow is that provided by elevation and the pressure head gradient becomes zero.

The third criterion in the design of a lysimeter is to ensure that the flux at the base of the cover layer is equal to the flux at the collection point within the lysimeter under a variety of surface flux conditions. To check the validity of the lysimeter design, it is fundamental to apply different surface flux boundary conditions to the model (O'Kane \& Barbour 2003) and study the lysimeter modelled performance under all potential conditions. 


\subsubsection{Numerical modelling of lysimeter geometry}

SEEP/W is a 2D finite element model that can be used to simulate the saturated and unsaturated movement of moisture and porewater pressure distribution within porous materials such as soil and rock. SEEP/W has application in the analysis and design for geotechnical, civil, hydrogeological, and mining engineering projects (Geo-Slope International Ltd 2014a).

VADOSE/W is a 2D finite element model (which can also perform one-dimensional (1D) simulations) that predicts pressure head (suction), hydraulic gradient, fluid fluxes and temperature profiles in the soil profile in response to climatic forcing (such as evaporation) and lower boundary conditions (such as a water table). A key feature of VADOSE/W is the ability of the model to predict actual evaporation and transpiration based on potential evaporation and predicted soil suction, as opposed to the user being required to input these surface flux boundary conditions. The actual evapotranspiration rate is generally well below the potential rate during prolonged dry periods because the suction, or negative water pressure, in the soil profile increases as the surface desiccates. In addition, VADOSE/W is a fully coupled (through the vapour pressure term) heat and mass transfer model which is capable of predicting water vapour movement (Geo-Slope International Ltd 2014b).

SEEP/W and VADOSE/W are part of the GeoStudio 2012 suite of programs, of which Version 8.13.1.9253 was used for this project.

Before numerical modelling can be undertaken the model inputs must be clearly defined. These inputs can be placed into four categories: material properties; upper boundary conditions; lower boundary conditions; and geometry. While the material properties and boundary conditions are fixed for all simulations, the geometry of the lysimeter is varied to develop the most adequate lysimeter configuration.

The material properties or functions required for each material in the VADOSE/W model are as follows:

- Soil water characteristic curve: (SWCC - suction versus volumetric water content) also known as a soil-water characteristic curve, is a continuous function relating energy and the state of water, and hence describes the water content of a material as a function of soil suction, or negative porewater pressure. The SWCC is central to the design of an unsaturated soil system, and the most fundamental characterisation required for design.

- Hydraulic conductivity function: (k-function - suction versus hydraulic conductivity) is a measure of the ability of a soil or rock material to transmit water, and is a maximum for saturated soil or rock materials. The saturated hydraulic conductivity (ksat) is a key input parameter to a soil-plant-atmosphere numerical model. K-functions are difficult to measure. Therefore, they are usually estimated based on ksat and the SWCC using an accepted method. For this project the k-functions were estimated using the Fredlund et al. (1994) method.

- Thermal conductivity function: (volumetric water content versus thermal conductivity) defines the ability of a soil medium to transmit heat by conduction. It is defined as the quantity of heat that will flow through a unit area of a soil medium of unit thickness in unit time under a unit temperature gradient. The thermal conductivity functions for all the materials were estimated using the Johansen (1975) method.

- Volumetric specific heat function: (volumetric water content versus volumetric specific heat) describes the relationship between volumetric water content and volumetric specific heat. The volumetric specific heat functions for all the materials were estimated using the de Vries (1963) method.

SEEP/W only requires the MRC and k-function for model development. 


\section{Case study of applied integrated numerical modelling for determining lysimeter design parameters}

The evaluation of lysimeter design options for field monitoring of a cover system over a mine waste facility located at Newmont Boddington Gold Mine (NBG), an open-cut gold mining operation in a semi-arid temperate region of Western Australia, is provided herein as a case study. The NBG cover system study provides an excellent example of an examination process using integrated numerical modelling methods of assessment to achieve numerical results to determine a preferred lysimeter design.

The key design criteria for the study was to minimise the influence of the lysimeter on measured percolation in order to ensure appropriate performance based on the LCR.

Two commercially available software packages were coupled to simulate net percolation flow rates through the cover system and waste material: Geostudio's VADOSE/W and SEEP/W modelling programs.

\subsection{Site background}

Newmont Boddington Gold is a large open-cut gold and copper mining operation located $130 \mathrm{~km}$ south-east of Perth in Western Australia. Newmont Asia Pacific is the sole owner and operator of the mine site consisting of two large hard rock open pits, with a current mine life of 2029, with processing of stockpiled material until 2032. The expected final footprint of the waste rock dumps (WRDs) is 811 hectares.

In 2014 NBG had initiated a multi-phase, multi-discipline research study in support of developing closure plans for the WRDs. A major component of this study is the construction of cover system field trial to examine field performance of the cover system under site specific conditions. A monitoring system for assessing the performance of the cover system field trial is required as part of the closure strategy for the WRD. O'Kane Consultants (OKC) assisted NBG in the design and installation of a lysimeter to determine net percolation rates through the cover system field trial constructed on the WRD. The design involved a 1D and 2D numerical modelling using the computer programs VADOSE/W and SEEP/W.

\subsection{Numerical modelling of lysimeter geometry}

\subsubsection{Material properties}

As laboratory data was unavailable for SWCC and hydraulic conductivity functions of the specific materials found on site, a set of material properties were estimated for the pertinent site materials (i.e. clay oxide, gravel, waste rock, and topsoil). This was done by comparing measured particle size distributions (PSDs) for these materials to similar materials in the OKC database that have known material properties and using information supplied by NBG. The walls and floor of the lysimeters are simulated as impermeable using null elements.

The water retention curves and hydraulic conductivity functions estimated for the materials are shown in Figures 2 and 3 , respectively. 


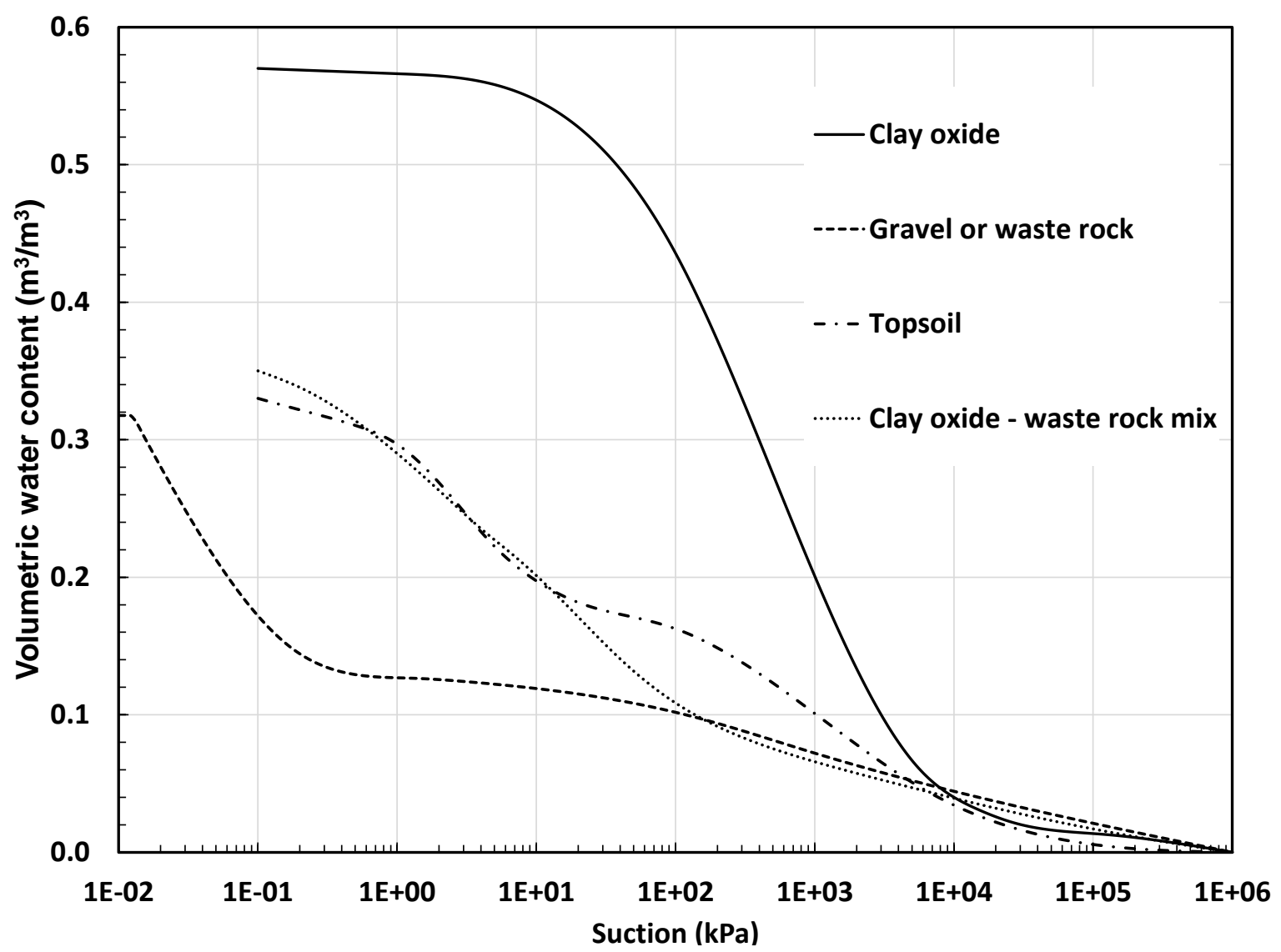

Figure 2 Soil water characteristic curves used to simulate project materials

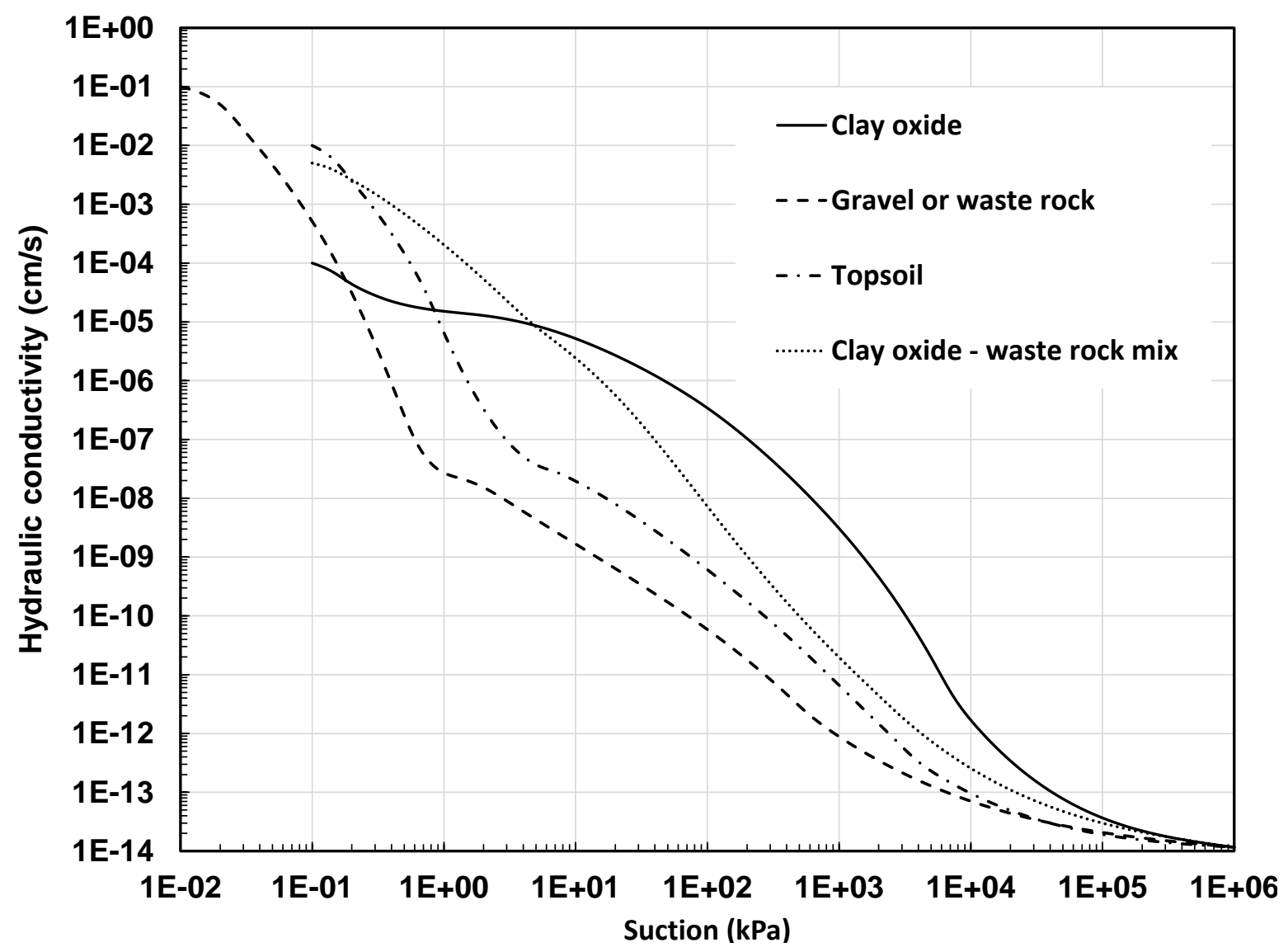

Figure 3 Hydraulic conductivity functions used to simulate project materials 


\subsubsection{Upper boundary conditions}

Climate data is inputted to VADOSE/W for upper boundary conditions while SEEP/W requires a surface flux boundary. Results from the 1D VADOSE/W modelling are used for the surface flux boundary rates required for the 2D SEEP/W Simulations.

\subsubsection{Climate data}

A historic 75-year climate database developed for the site was estimated from climate data obtained from meteorological stations established surrounding the site. The 75-year climate database was evaluated to determine the most representative 20 -year period for the site. The average annual rainfall for the chosen 20 year period is similar to the average for the 75-year climate database, and includes relatively high and low rainfall years compared to the annual average. It was therefore considered to offer a good representation of the entire data set.

\subsubsection{Surface flux boundary}

For lysimeter design modelling, the upper boundary condition is the net percolation rate anticipated to flow through the material profile. Surface flux boundary conditions for the steady-state SEEP/W simulations were set based on the results of the 1D soil-atmosphere modelling, with the base flux rate being $1.5 \%$ of precipitation ( $11 \mathrm{~mm} / \mathrm{yr}$ ); which is estimated to represent over $90 \%$ of daily net percolation rates. Although atmospheric conditions could have been applied to the 2D model, deriving a steady-state flux from the 1D VADOSE/W model allows to greatly simplify the 2D modelling, given the number of simulations performed. Two states of surface flux boundaries were modelled, representing high and low annual NP. Results for lysimeter performance were generally better under high NP conditions than under low NP conditions. The performance of lysimeter configurations under low NP was therefore determined to be the better parameter for determining the optimal lysimeter configuration.

\subsubsection{Lower and edge boundary conditions}

The simulations used a constant pressure head corresponding to the surface flux rate being applied for the lower boundary condition. The lower boundary was placed approximately $10 \mathrm{~m}$ below the surface so that it did not influence the simulated performance of potential lysimeter designs.

The edge boundaries for all the scenarios were simulated as no-flow boundaries. However, each simulation was completed with the edge boundaries at least $10 \mathrm{~m}$ away from the sidewalls of the lysimeter to ensure that the edges of the model were at a sufficient distance from the area of the lysimeter to not influence modelling results.

\subsubsection{Geometry}

Figures 4 and 5 are the overall geometry of the 1D soil-atmosphere and 2D seepage models, respectively with regions, points, lines, mesh and boundary conditions shown. The 1D soil atmosphere model geometry represents a cross sectional column of the cover system design.

The 2D seepage modelling considered four design elements to determine the optimum lysimeter configuration:

- Lysimeter width - tank (2.5 m width) versus large scale (10 m width) lysimeter.

- Wall height - varied between 0.5 and $2.3 \mathrm{~m}$.

- Depth of lysimeter below barrier layer - varied between $1 \mathrm{~m}$ below and contacting the lower boundary of the barrier layer.

- Slope of layering - no slope and 5\% slope angle. 


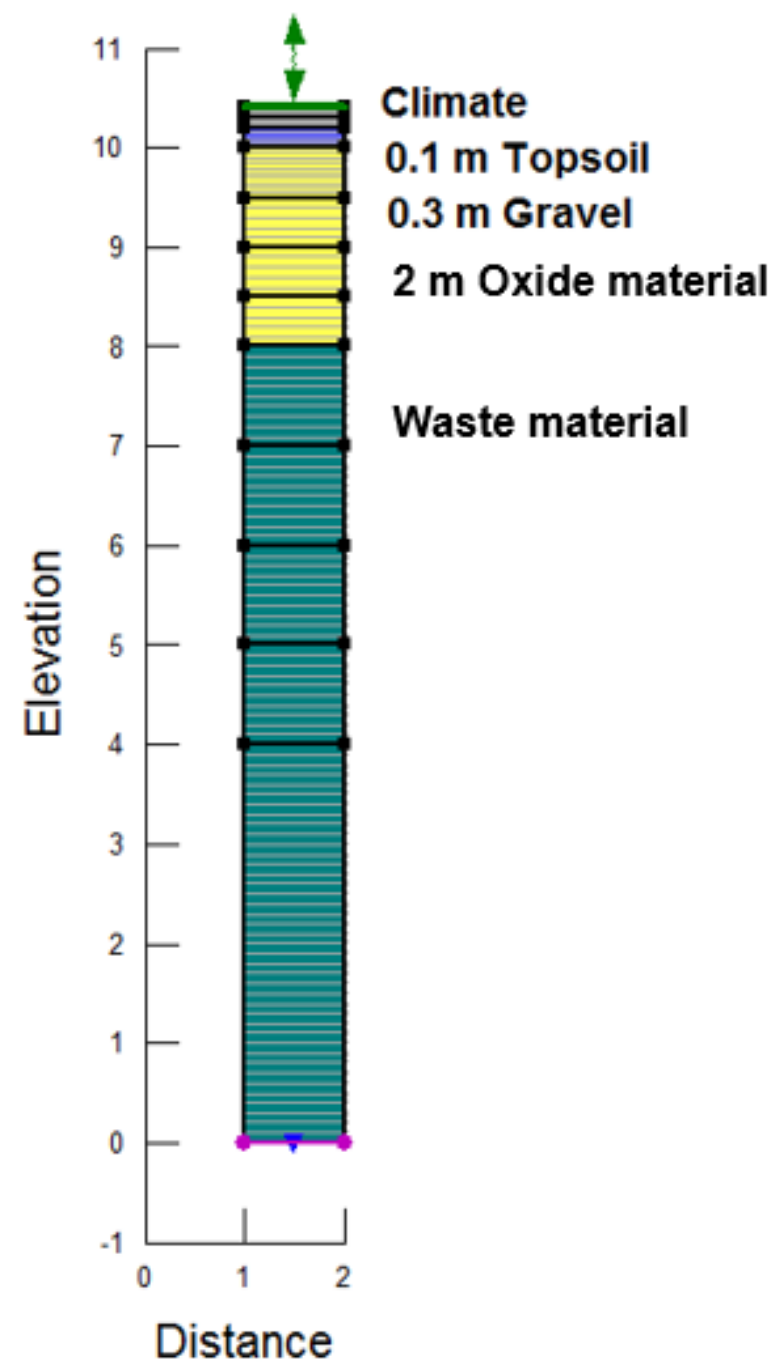

Figure 4 1D soil-atmosphere model geometry

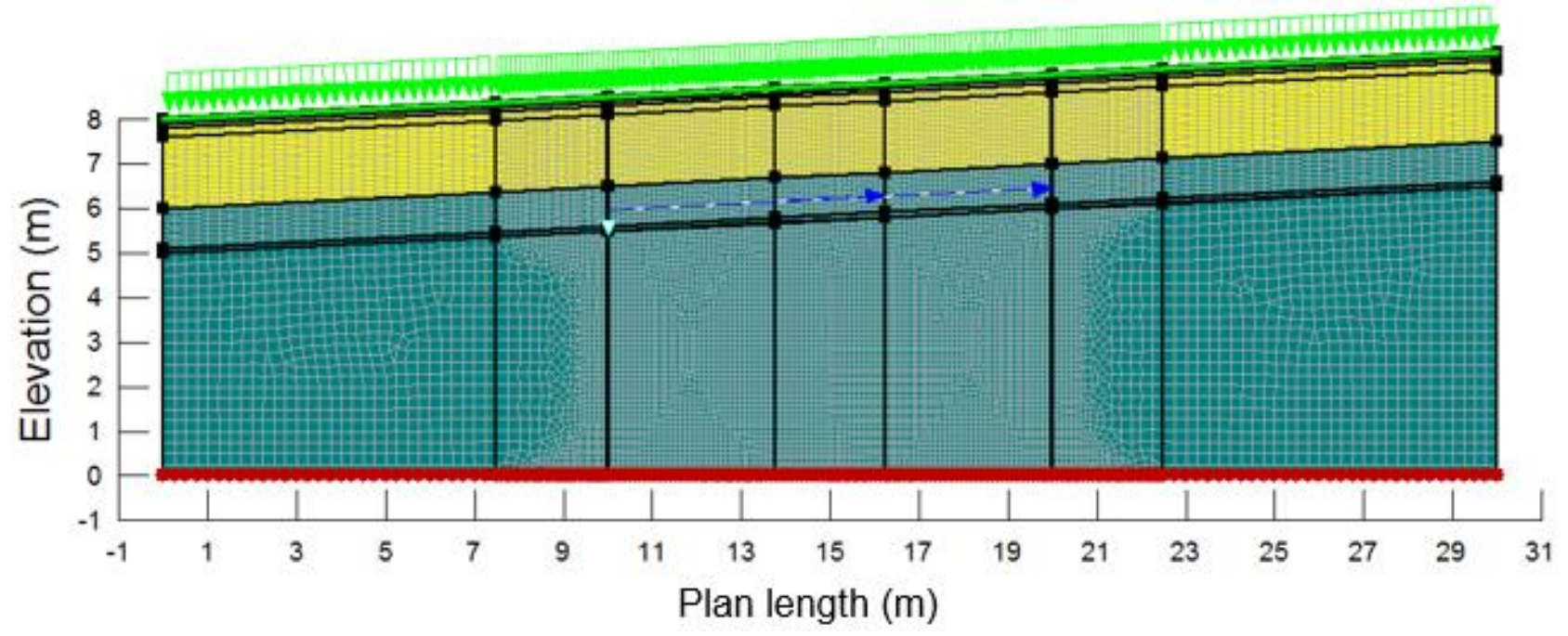

Figure $52 \mathrm{2D}$ seepage model geometry

\subsection{Modelling results}

Ninety 2D steady-state seepage simulations were completed to determine the most effective NBG lysimeter design. 


\subsubsection{Width}

Two lysimeter widths were evaluated for this project: $2.5 \mathrm{~m}$, which represents a tank lysimeter, and $10 \mathrm{~m}$, which represents a large scale lysimeter. Both lysimeter designs can perform well if designed properly. However, under the conditions modelled for this site, tank lysimeters were not as robust, as shown by larger reductions in LCR when other design elements were not optimised. For example, models \#11 and \#56 are identical scenarios except for lysimeter width, but the tank lysimeter results showed only $0.07 \%$ of the actual net percolation reporting at the base whereas the large scale lysimeter still measures $76 \%$ of the actual net percolation. Under all scenarios modelled, all else being equal, the large-scale lysimeter constantly resulted in a better LCR than the tank lysimeter for the site's conditions.

\subsubsection{Wall height}

Wall height is the most important lysimeter design element controlling performance and additional height only benefits performance as shown in Figure 6, where modelling results for varying wall heights are presented as they relate to the LCR of a given configuration. Based on the results, it was recommended that the tank lysimeter used a maximum wall height of $2.5 \mathrm{~m}$ and the large scale lysimeter have a minimum wall height of $1.5 \mathrm{~m}$.

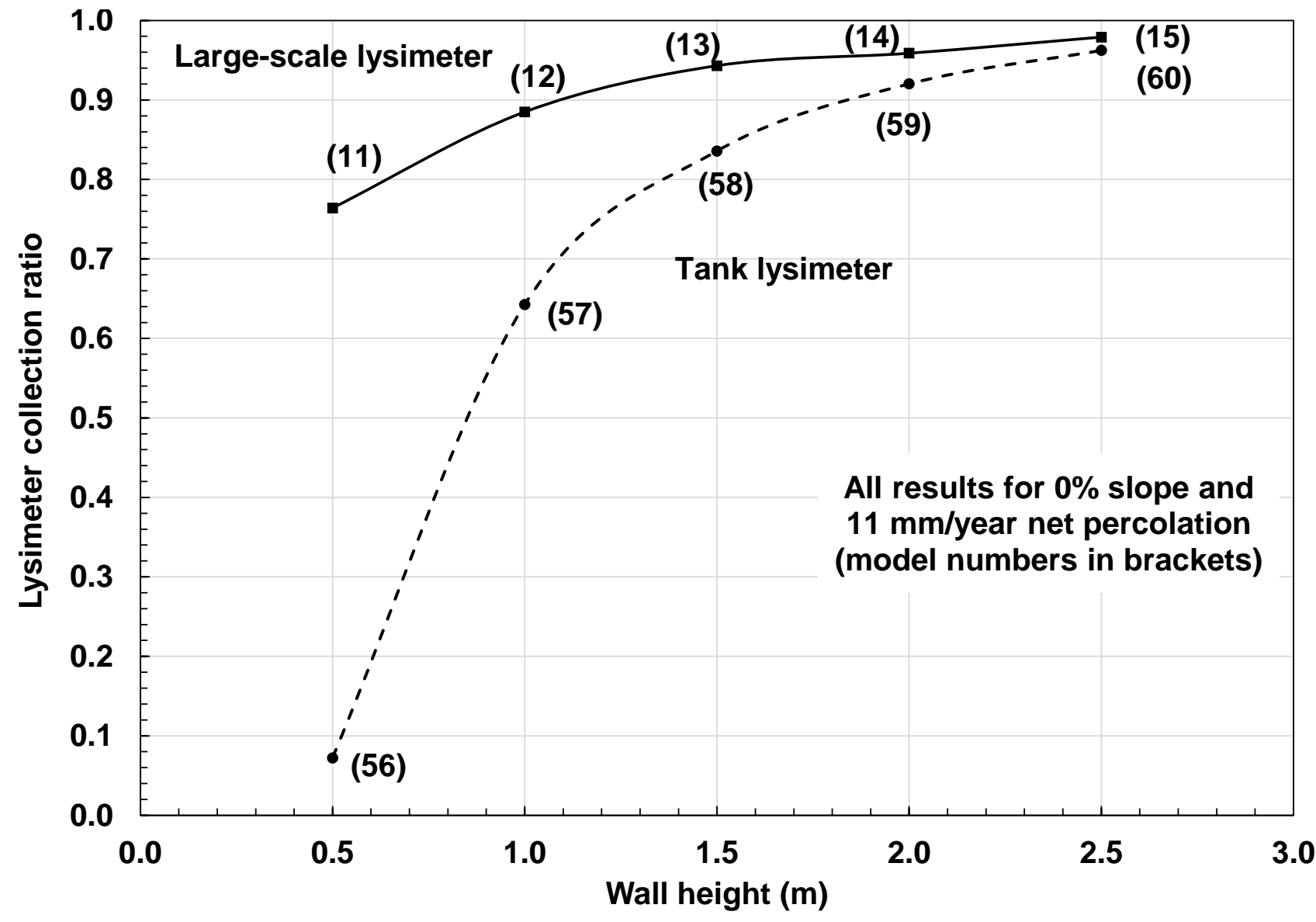

Figure 6 Example of change in LCR with increasing sidewall height of the tank and large scale lysimeters

\subsubsection{Depth below the cover system}

As presented in Figure 7, the models show that the lysimeters perform better when not in direct contact with the cover system. When low flux events are measured from the lysimeter, lowering the lysimeter position enhances the LCR for the system. Therefore, based on the modelling results, the improved accuracy indicates that installing the lysimeter at $1 \mathrm{~m}$ below the cover system would provide the best results in capturing NP. 


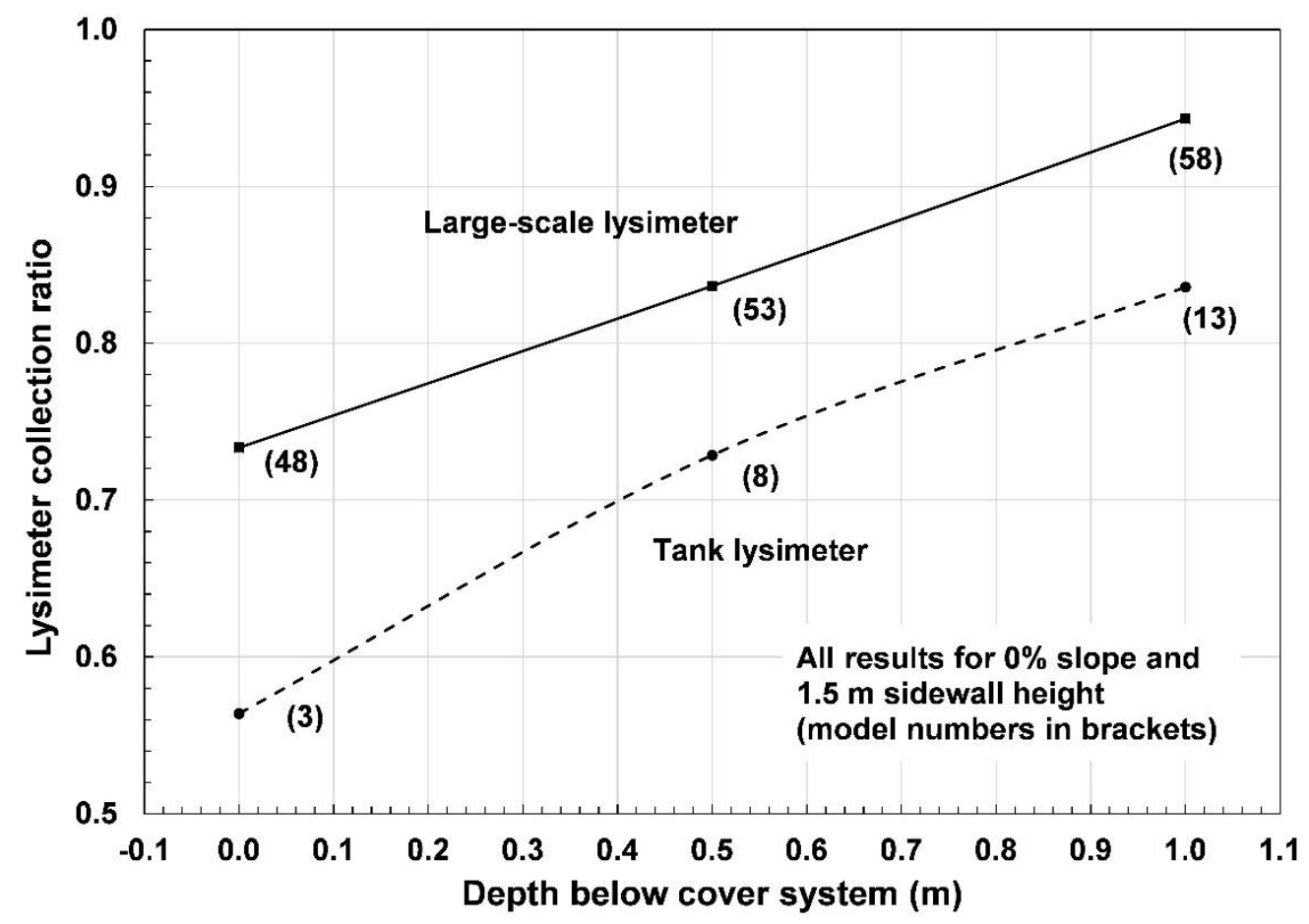

Figure 7 Example of change in LCR with increasing depth below the cover system of the tank and large scale lysimeters

\subsubsection{Slope of cover system}

Two options were initially considered for construction of the lysimeter: on the plateau area and on the embankment at a $40 \%$ gradient. Performance for both lysimeter types, tank and large-scale, were evaluated when placed on a slope as opposed to a horizontal platform. Due to the difficulty of modelling the lysimeter under a steep slope profile, it was decided to run the simulations under a reduced $5 \%$ gradient to estimate the effect of the slope. Both lysimeters were simulated with a $5 \%$ gradient with similar sidewall height and depth specifications. The modelling results shown in Figure 8 show that placing the lysimeter under a slope profile is detrimental to the lysimeter performance for all cases studied. Based on these modelling results, it is evident that the location of the lysimeter is preferred at the plateau area and putting the lysimeter on the side slope (at $40 \%$ gradient) would be detrimental to performance.

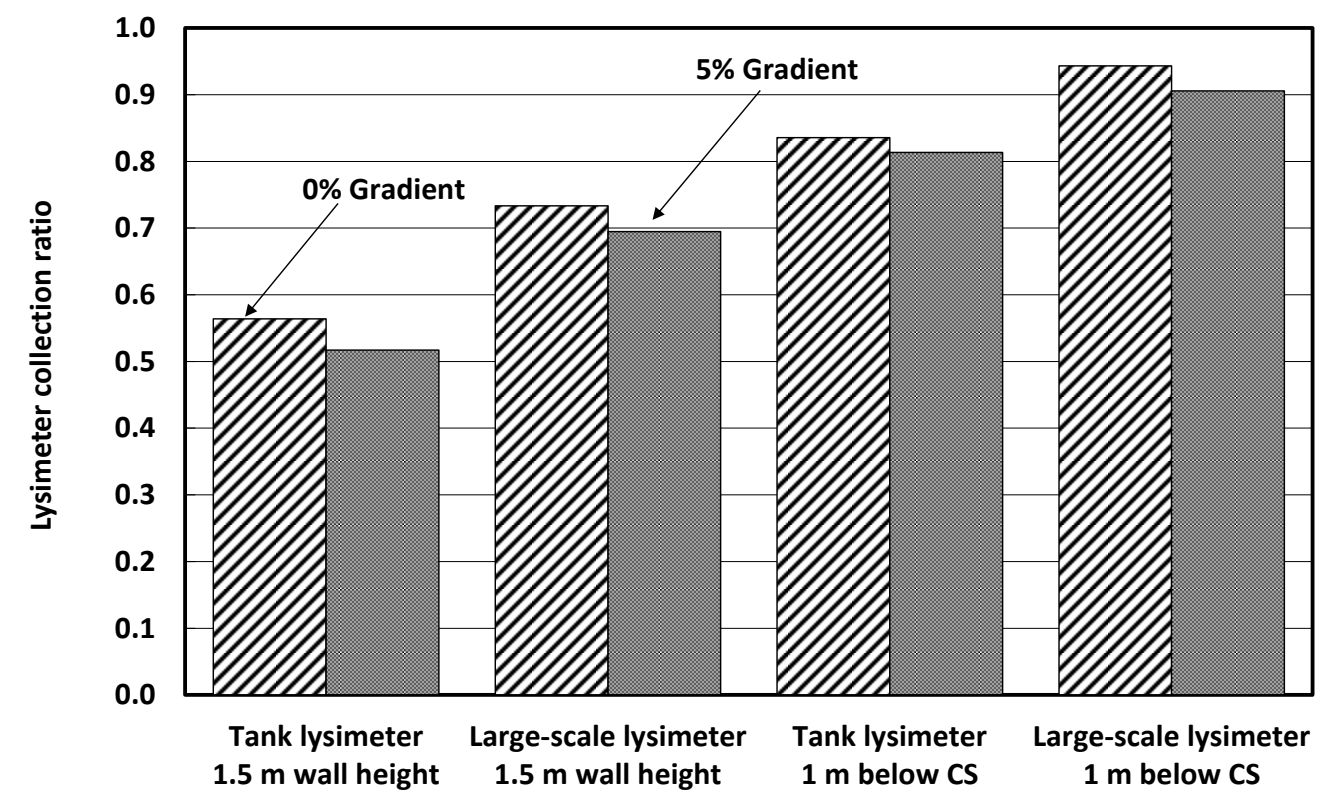

Figure 8 Example of difference in LCR for placing the lysimeter on a horizontal ground and $5 \%$ slope 


\subsection{Final design}

In terms of LCR, the large scale lysimeter performed better than the tank lysimeter. The large scale lysimeter will also include, from a qualitative perspective, a greater level of heterogeneity inherent to the cover system due to it monitoring a larger area of the cover system. Hence, the large scale lysimeter will more effectively achieve the objective of monitoring the net percolation rate. O'Kane Consultants recommended that a large scale lysimeter with a length of $10 \mathrm{~m}$, minimum width of $10 \mathrm{~m}$, and sidewall height of $1.5 \mathrm{~m}$ is utilised. The large scale lysimeter would address the need to capture the inherent spatial heterogeneity in cover characteristics, as well as changes to the cover system over time due to natural processes.

\subsection{Complementary instrumentation}

Lysimeters use direct measurement of net percolation. When properly designed, they are a valuable tool to measure net percolation and develop an understanding of the cover system performance under varying conditions. The simulated performance of a lysimeter should be considered relative until validated through field performance monitoring, which would consist of monitoring in situ moisture and pressure conditions inside and outside the confines of the lysimeter. This is to confirm that the lysimeter is performing as intended in response to the in situ material properties and climatic conditions. A complete performance monitoring system requires complementary instrumentation.

In order to confirm the performance of the installed cover system, other elements of the water balance of the cover profile must be measured. The performance monitoring system installed at NBG consists of six sensor nests positioned both on the plateau area and on the slope. Two sensor nests monitor conditions within and external to the lysimeter on the plateau. Four sensor nests are positioned on the slope area and monitor two of the three soil profiles, each with a primary and secondary sensor nest.

\subsubsection{Volumetric water content}

Volumetric water content sensors are placed through the profile at each nest location. Changes in moisture storage conditions are measured and allow the evaluation of the relative performance of the cover profiles as well as measuring the potential influence of the presence of the lysimeter on local moisture conditions, which would in turn impact net percolation measurements from the lysimeter. Sensor nests placed on the slope will allow the measurement of the impact of the slope profile on net percolation.

\subsubsection{Hydraulic gradient}

Through the measurement of in situ matric suction, it is possible to calculate the hydraulic gradient between two soil profile layers and, with moisture content measurements, calculate the fluxes through a section of the soil profile. Suction sensors were included in four of the six sensor nests installed.

\subsubsection{Runoff}

Runoff volumes on the slope and plateau are monitored with pre-fabricated fiberglass flumes specifically designed for the anticipated runoff volumes on site, and are equipped with a pressure transducer to measure stage height in the flume. The flume is provided with a rating curve (calibration) which allows for flow volumes to be determined by a given water stage height. Stage height is continuously monitored by the pressure transducer and controlled by the plateau and slope data acquisition system.

\subsubsection{Lateral percolation}

An interflow collection system was installed to collect and measure sub-surface water present within the gravel layer of the cover profile. Lateral percolation is monitored by an interflow collection system, and is located within the runoff and erosion monitoring area on the slope trial. Given the low hydraulic conductivity of the oxide material, it is anticipated that preferential flow above this layer and within the gravel layer could 
occur. Monitoring of interflow volumes provides key information for water balance calculations, and for determining effective hydraulic conductivity.

\section{Conclusion}

Lysimeters and complementary instrumentation are widely used in the mining and waste industries to monitor the performance of cover systems installed for the rehabilitation of containment facilities in regards to net percolation and oxygen flux. Although the operating principles are generally well understood, the design and installation of lysimeters is complex and requires modelling of the lysimeter design parameters and configuration to minimise the influence of the lysimeter on measured percolation. Appropriate numerical modelling will ensure that the LCR is adequate for a given design in addition to comparing conditions inside and outside the lysimeter confines in regards to pressure head profiles, hydraulic gradients and fluxes at the base of the cover and at the lysimeter collection point.

Following construction, lysimeter performance needs to be closely monitored to ensure adequate operation. Installation of complementary monitoring equipment is required to enhance understanding of the processes involved with net percolation and validate monitoring data from the lysimeter. Indirect methods for measuring net percolation can be used to verify a lysimeter's performance or, in the absence of a lysimeter, as the main method to determine net percolation.

\section{Acknowledgement}

O'Kane Consultants acknowledge the contribution and support of NBG personnel during the design and installation phases of the large scale lysimeter.

\section{References}

Bews, BE, O'Kane, MA, Wilson, GW, Williams, D \& Currey, N 1997, 'The design of a low flux cover system, including lysimeters, for acid generating waste rock in semi-arid environments', in Proceedings of the Fourth International Conference on Acid Rock Drainage, Vancouver, pp. 747-762.

de Vries, DA 1963, 'Thermal properties of soils', in WR Van Wihk (ed), Physics of Plant Environment, North Holland Pub. Co, pp. 382.

Fredlund, DG, Xing, A \& Huang, S 1994, 'Predicting the permeability function for unsaturated soils using the soil-water characteristic curve', Canadian Geotechnical Journal, vol. 31, pp. 533-546.

Geo-Slope International Ltd 2014a, Seepage modeling with SEEP/W - an engineering methodology, May 2014 Edition, GEO-SLOPE International Ltd.

Geo-Slope International Ltd 2014b, Seepage modeling with VADOSE/W - an engineering methodology, May 2014 Edition, GEO-SLOPE International Ltd.

Johansen, O 1975, 'Thermal Conductivity of Soils', PhD Thesis, (CRREL Draft Translation 637, 1977), Trondheim, Norway.

MEND 2004, Design, construction and performance monitoring of cover systems for waste rock and tailings, Canadian Mine Environment Neutral Drainage Program, Project 2.21.4, July.

O'Kane, M 2011, 'State-of-the-art performance monitoring of cover systems - Moving from point scale to macro scale approaches', 7 th Australian Workshop on Acid and Metalliferous Drainage (AMD), Darwin, June.

O'Kane, M \& Ayres, B 2012, 'Cover systems that utilise the moisture store-and-release concept - do they work and how can we improve their design and performance?' in AB Fourie \& M Tibbett (eds), Proceeding of the Seventh International Conference on Mine Closure, Australian Centre for Geomechanics, Perth, pp. 407-416.

O'Kane, M \& Barbour, SL 2003 'Field performance of lysimeters used to evaluate cover systems for mine waste', in Proceedings of the Sixth International Conference for Acid Rock Drainage, Cairns, pp. 327-339. 